\title{
Management of Oral Sub-Mucous Fibrosis: An update
}

\author{
SMA SADAT $^{\mathrm{a}}$, MS BENZADID ${ }^{\mathrm{b}}$, M NUSRATH $^{\mathrm{c}}, \mathrm{SN}^{\mathrm{RITA}}{ }^{\mathrm{d}}$
}

\begin{abstract}
:
Oral submucous fibrosis (OSMF) is a complex, debilitating, and precancerous condition. Formerly restricted to the Indian subcontinent, it is now frequently seen in the Asian communities of the United Kingdom, the United States, and other developed countries, and thus constitutes a severe global health problem. Areca-nut, the well-known causative agent of the disease, is now recognized as a group one carcinogen. Several grading systems and management protocols have been published in the literature to deal with this progressive
\end{abstract}

Introduction:

Oral sub mucous fibrosis (OSMF) is a chronic progressive debilitating disease most frequently seen in South and South East Asia or emigrants from these areas. ${ }^{1}$ The presentation of oral sub mucous fibrosis is now called a "potentially malignant disorder ". The progressive irreversible fibrosis of the submucosa leads to trismus, an inability to consume the average spicy food that people in the subcontinent are used to, and carries a high risk of malignant transformation. ${ }^{2}$ The most widely accepted definition of the disease by Pindborg and Sirsat ${ }^{2}$ is one of an insidious, chronic disease that affects any part of the oral cavity and sometimes the pharynx. The definition by the World

a. Dr. S. M. Anwar Sadat, Associate Professor, Dept. of Oral and Maxillofacial Surgery, Dhaka Dental College, Mirpur14, Dhaka, Bangladesh.

b. Dr. Md. Shadly Benzadid, HMO, Dept. of Oral and Maxillofacial Surgery, Dhaka Dental College, Mirpur-14, Dhaka, Bangladesh.

c. Dr. Muzzammil Nusrath, Consultant Maxillofacial Surgeon, Sheffield Teaching Hospitals, UK

d. Dr. Sufia Nasrin Rita, Professor and Head, Dept. of Orthodontics, Sapporo Dental College, Uttara, Dhaka, Bangladesh.

Address of Correspondence: Dr. S. M. Anwar Sadat, Associate Professor, Dept of Oral and Maxillofacial Surgery, Dhaka Dental College, Mirpur-14, Dhaka, Bangladesh. Mobile: +8801711156023, E-mail: an_sadat@yahoo.com,

Received: 22 August, 2019 Accepted: 25 March, 2020
disease.Despite the numerous medical methods used in oral sub mucous fibrosis management, sometimes surgical intervention becomes inevitable. Here, we extensively reviewed existing literature to discuss about incidence, presentation, aetio-pathogenesis, medical and surgical management with outcome of OSMF.

Keywords: Areca nut, Arecoline, Fibrous Band, Oral Submucous Fibrosis, Reconstruction.

(J Bangladesh Coll Phys Surg 2020; 38: 135-144) DOI: https://doi.org/10.3329/jbcps.v38i3.47061

Health Organization (WHO) of a precancerous oral condition: "a generalized pathological state of the oral mucosa associated with a significantly increased risk of cancer" fits well with the characteristics of OSMF. 3,4 The disease is believed to be multi-factorial in origin with an elevated prevalence in individuals who chew areca-nut and a substantial rate of malignant transformation (7-30\%) presents worldwide public health issues. ${ }^{5,6}$

Most treatment options in OSMF focused on relieving the burning sensation and releasing fibrotic bands to help with oral opening. The release of fibrotic bands has been predictably the foundation of all surgical methods, while medical procedures focused on suppressing the inflammatory response and preventing progressive fibrosis ${ }^{7}$. The medical management includes multiphase injections of hyaluronidase, hydrocortisone, placental extract, and triamcinolone plus vitamin and iron supplements while various surgical modalities include release of fibrous bands and covering of the raw areas with split thickness skin grafting, bilateral nasolabial flaps, palatal island flaps, tongue flaps, temporalis myotomy and coronoidectomy. ${ }^{8,9}$ The purpose of this review is to discuss all of OSMF's elements including terminology, epidemiology, etiopathologenesis and provide a short summary of medical and surgical management. 


\section{Terminology}

More than half a century has passed since Schwartz described oral sub-mucous fibrosis in Indian tobaccochewing females in East Africa. ${ }^{10}$ In 1952, Schwartz described a condition in 5 Indian women that he called "atrophiaidiopathies (tropica) mucosae oris"11; Joshi established the term "sub-mucous fibrosisof the palate and pillars". ${ }^{12}$ Pindborg and Sirsat used the term "submucousfibrosis" although they recommended that a more appropriatename would be "juxtaepithelial fibrosis". ${ }^{2}$ Other names suggested include "diffuse oral submucous fibrosis", "idiopathic sclerodermaof the mouth", "idiopathic palatal fibrosis", and "sclerosingstomatitis"., ${ }^{24}$ Paymaster first described its pre-malignant nature in $1956 .{ }^{13}$

\section{Epidemiology}

Geographically, OSMF has a specific distribution and affectspredominantly Asians (and particularly Indians) from thesouthernstates, and Taiwanese. ${ }^{14,15}$ Other series of OSMFin Europe, the Far East, and the Pacific Rim have also beenreported. ${ }^{5,14,15}$ An estimate from 1996 stated that around 2.5 million individuals worldwide have OSMF. ${ }^{5,16}$ Furthermore, it is estimated that up to $20 \%$ of the world's population consumes betel nut in some form, so the incidence of OSMF is likely greater than in the literature released. ${ }^{17}$

Oral cancer in those who chew betel quid is one of the most prevalent malignancies in the nations of South and Southeast Asia ${ }^{18,19}$ and with immigration from the Indian subcontinent to the UK,USA, and South Africa, oral and maxillofacial surgeons inthese countries are likely to encounter the disease. ${ }^{5}$ According to a 2009 survey targeting all men and women aged 15 years or more in Bangladesh, betel was used by both men (23.5\%) and women (25.2\%). ${ }^{20}$ Recent investigations into betel quid chewing in the UK have found the habit to be widespread among Bangladeshis. ${ }^{21,22}$ Previous studies showed that $95 \%$ of Bangladeshi women in West Yorkshire chewed betel quid, of whom $89 \%$ added tobacco where in Birmingham, 96\% of Bangladeshi women and $92 \%$ of Bangladeshi men reported chewing betel quid, of whom $81 \%$ of the women and $37 \%$ of the men added tobacco. 22,23

Epidemiological data and intervention studies suggest that areca nut (Supari) is the main etiological factor for OSMF. ${ }^{24-38}$ Areca nut is believed to be the fourth most addictive substance in the world ${ }^{(17)}$. Other etiological factors suggested are chilies, lime, tobacco, nutritional deficiencies such as iron, zinc, and copper, immunological disorders, collagen disorders, and genetic predisposition.

There is a wide variation in the range of ages as reported by various authors. Pindborg et al. reported average age range as 53.6 years for males and 37.7 years for females ${ }^{29}$ however, recent authors, report incidence of OSMF mostly in the younger population age ranging from 20 to 30 years. ${ }^{12,30-33}$ In a study reported by Babu et al. and Trivedy et al. on OSMF, $23 \%$ of patients were of ages between 14 and 19 years. ${ }^{34,35}$ In another study by Anuj Jain ${ }^{(36)}$ stated that the youngest patient reported to be suffering from OSMF was of 2.5 years old. The precancerous nature of oral sub-mucous fibrosis has been observed with development of slowly growing squamous cell carcinoma in one-third of oral submucous fibrosis patients according to Paymaster. ${ }^{13}$ Recent studies have shown that as many as $19 \%$ of oral sub-mucous fibrosis patients develop oral carcinoma ${ }^{37,38}$ but other studies claim that the malignant transformation rate of OSMF is 7 to 30 percent. ${ }^{2,39,40}$

\section{Etio-pathogenensis}

OSMF was initially believed to be idiopathic, but epidemiological data and intervention studies suggest that it has multifactorial in origin and areca nut (Supari) is the main etiological factor for OSMF. ${ }^{24-28}$ Areca nut is believed to be the fourth most addictive substance in the world. ${ }^{17}$ Other etiological factors suggested are chilies, lime, tobacco, nutritional deficiencies such as iron, zinc, and copper, immunological disorders, collagen disorders, and genetic predisposition. A possible autoimmune role and genetic predisposition for the disease (OSMF) with demonstration of various autoantibodies and an association with specific HLA antigens A10, DR3, DR7, and probably B7, along with haplophyticpairs A10/DR3, B8/DR3, and A10/88, has been found. ${ }^{42,43}$

However, there have been overwhelming proof from multiple epidemiological studies, large cross-sectional surveys, case-control studies, and cohort and intervention research that areca-nut is the major etiological factor in OSMF. ${ }^{25-28,30,43-50}$ Four alkaloids have been conclusively identified in biochemical studies, arecoline, arecaidine, guvacine, and guvacoline, 
of which arecoline is the main agent.Arecoline an alkaloid component of areca nut, stimulates fibroblastic proliferation and collagen synthesis. Flavonoids (tannins and catechins) inhibit collagenase, stabilize fibrils of collagen and make them resistant to collagenase degradation. ${ }^{14,43,51-53}$

An initial epithelial inflammation is followed by fibroelastic changes in the lamina propria. ${ }^{18,45}$ Dense fibrotic bands are formed by epithelial atrophy and collagen deposition. Over activity during chewing creates ischemic changes. The subsequent fibrosis and scarring of the masticatory muscles further lead to the formation of fibrotic bands and trismus. These bands are visible in the palate, buccal and labial areas and, in later stages, in the pharyngeal and oesophageal areas. ${ }^{54}$

\section{Clinical Features}

Initially, most patients present with a burning sensation orintolerance to spicy food, and they may have vesicles, particularly on the palate. Ulceration and dryness of the mouth islater followed by fibrosis of the oral mucosa, which leads torigidity of the lips, tongue, and palate, and trismus ${ }^{14}$ Petechiae, in the absence of blood dyscrasias or systemicdisorders, are found in about $22 \%$ of patients with OSMF,occur most often on the tongue followed by the labialand buccal mucosa. ${ }^{4,55}$

A useful clinical sign is pain on palpation in the sites wheresubmucosal fibrotic bands are developing, and trismus iscaused mostly by fibrosis in the dense tissue around the pterygomandibular raphe. ${ }^{55}$ Fibrosis of the eustachian tube maylead to deafness. ${ }^{5,56}$ When the fibrosis involves the nasopharynx or esophagus, patients may experience referred pain tothe ear, a nasal voice, and dysphagia to solids; usually theseare features of more advanced disease. .,55 $^{5,5}$

The most obvious clinical signs include blanched, opaqueoral mucosa with palpable fibrous bands. ${ }^{14,57,58}$ Furthermore, the overlying epithelium may become dysplasticand malignant.

\section{Histopathology}

Histopathology (HP) does not seem to play a much significant role in the diagnosis of OSMF as most clinicians diagnose OSMF based on clinical findings. However, this does not undermine in any way importance of HP studies. The early histological changes present as chronic inflammatory cell infiltration of sub epithelial connective tissues. This otherwise nonspecific infiltrate usually contains a number of eosinophils, which are not usually found in oral inflammation. ${ }^{59}$ This is followed by a strong fibro-elastic response resulting in the formation of fine, fibrillar collagen bundles. The histological changes in established cases include atrophy of the epithelium, together with a keratinizing metaplasia and the accumulation of hyalinizedsubepithelial collagen and a progressive loss of vascularity ${ }^{59}$ Canniff $^{60}$ found that $87 \%$ of 44 patients with oral sub mucous fibrosis showed an atrophic epithelium, the epithelium in $67 \%$ had undergone a keratinizing metaplasia, 27\% showed mild atypiaand $100 \%$ showed presence of juxta-epithelial collagen.

Very affordable immunohistochemistry in the form of Silver binding nucleolar organiser regions (AgNORS) also known as "poor mans Immuno" can be used for prognostication of Oral Submucous fibrosis (M A Nusrath 1997, Thesis Masters Course, University of Gujrat, India). Comparison of moderate OSMFS with advanced OSMF was significant with a t value of 3.62 and $\mathrm{p}$ being $<0.005$. Comparison of advanced OSMF with moderately diff SCC was significant with a t value of 3.02 and $p$ being $<0.005$. The study along with other numerous studies showed that AgNORS can be used for prognostication of OSMF and were good alternative for immune especially for developing countries.

\section{Staging}

To aid in treatment planning Khanna and Andrade ${ }^{61}$ developed a classification system of OSMF based on inter incisal opening (MIO) as follows:

\&'Group I: This is the earliest stage and is not associated with mouth opening limitations. It refers to patients with an inter incisal distance of greater than $35 \mathrm{~mm}$.

\&'Group II: This refers to patients with an inter incisaldistance of $26-35 \mathrm{~mm}$.

\&'Group III: These are moderately advanced cases. This stage refers to patients with an inter incisal distanceof 15-26 mm. Fibrotic bands are visible at the softpalate, and pterygo-mandibular raphe and anteriorpillars of fauces are present.

\&'Group IVA: Trismus is severe, with an inter incisal distance of less than $15 \mathrm{~mm}$ and extensive fibrosis of all the oral mucosa. 
\&'Group IVB: Disease is most advanced, with premalignant and malignant changes throughout the mucosa.

Pindborg et $\mathrm{al}^{62}$ described consecutive stages of oral sub mucous fibrosis based on histologic findings: very early stage, early stage, moderately advanced stage, and advanced stage.

S. M. Haider et $\mathrm{al}^{63}$ gave the following staging system:

\section{Clinical and Functional Staging}

\section{Clinical Stage}

1. Faucial bands only

2. Faucial and buccal bands

3. Faucial, buccal, and labial bands

\section{Functional Stage}

A Mouth opening $20 \mathrm{~mm}$

B Mouth opening 11-19 mm

C Mouth opening $10 \mathrm{~mm}$

\section{Management}

The management of an OSMF patient depends on the degree of clinical involvement. It comprises of: discontinuation of areca-nut relatedhabit, nutritional support and antioxidants, physiotherapy, immunomodulatory drugs (steroids) for local/systemic application, intra-lesionalinjections of steroids, hyaluronidase, human placental extracts etc, either singly or in combination for early/milder form of disease and surgical measures for advanced cases with postoperative nutritional support and anti-oxidants along with active physiotherapy to prevent contracture at the surgical siteand recurrence. ${ }^{54}$

\section{Medical management}

The noninvasive treatment regimens include dietary supplementation with iron, Vitamin A or Vitamin B and anti-inflammatory agents like steroids as well as injection of degradative enzymes to facilitate fibrous tissue removal. This may give temporary relief but aggravates fibrosis because of the multiple needle insertion and irritation from the drug. ${ }^{64}$ The medical management is palliative therapy which is not going to reverse the condition completely. ${ }^{65}$ Patient has to quit the habit, along with long duration of medication will benefit in mild to moderate way which is not up to the satisfaction of patient or original mouth opening ${ }^{66,67}$ It will be useful in some extent only; if patient is in stage I transition where the burning sensation for hot spicy foods is started but no limited of mouth opening will be benefited. ${ }^{68}$

The medical management has been summarized in the following table given by Auluck et al ${ }^{69}$

Table-I

Treatment modality for OSF (Auluck et al. 2008)

\begin{tabular}{|c|c|}
\hline Treatment & Treatment Details \\
\hline Micronutrients and minerals & $\begin{array}{l}\text { Vitamin A, B complex, C, D and E, iron, copper, calcium, zinc, magnesium, } \\
\text { selenium and others }\end{array}$ \\
\hline Milk from immunized cows & $45 \mathrm{~g}$ milk powder twice a day for 3 months \\
\hline Lycopene & $8 \mathrm{mg}$ twice a day for 2 months \\
\hline Pentoxyfilline & $400 \mathrm{mg} 3$ times a day for 7 months \\
\hline Interferon gamma & $\begin{array}{l}\text { Intralesional injection of interferon gamma }(0.01-10.0 \mathrm{U} / \mathrm{mL}) 3 \text { times a day for } \\
6 \text { months }\end{array}$ \\
\hline Steroids & $\begin{array}{l}\text { Submucosal injections twice a week in multiple sites for } 3 \text { months/ Topical } \\
\text { for } 3 \text { months }\end{array}$ \\
\hline \multicolumn{2}{|l|}{ Placental extracts } \\
\hline Turmeric & $\begin{array}{l}\text { Alcoholic extracts of turmeric }(3 \mathrm{~g}) \text {, turmeric oil }(600 \mathrm{mg}) \text {, turmeric oleoresin } \\
(600 \mathrm{mg}) \text { daily for } 3 \text { months }\end{array}$ \\
\hline $\begin{array}{l}\text { Chymotrypsin, hyaluronidase } \\
\text { and dexamethasone }\end{array}$ & $\begin{array}{l}\text { Chymotrypsin ( } 5000 \mathrm{IU}) \text {, hyaluronidase ( } 1500 \mathrm{IU}) \text { and dexamethasone }(4 \mathrm{mg}) \text {, } \\
\text { twice weekly submucosal injections for } 10 \text { weeks }\end{array}$ \\
\hline
\end{tabular}




\section{Micro nutrients and minerals}

Few studies conducted in the previous decade observed that Vitamin A given at a concentration of 50,000 IU would cause symptomatic improvement ${ }^{64,70,71}$ On the other hand Reddi ${ }^{72}$ suggested thatVitamin $\mathrm{E}$ given concomitantly with the Hyalase and betamethasone was better than as compared with Hyalase and betamethasone alone. It was believed that Vitamin $\mathrm{C}$ reduces the edema between the collagen bundles and helps in regeneration of new collagen bundles with good approximation. ${ }^{73}$ Other than vitamins several minerals also have been used as an adjunctive in treatment of OSMF. Anil et al. ${ }^{70}$ administered Zinc $(220 \mathrm{mg})$ in combination with vitamin A and observed good results. Zinc plays essential role in DNA synthesis and cell division.

\section{Antioxidants}

Gupta et al., ${ }^{74}$ carried out a study on 34 cases of OSMF. They have advocated one tablet of antioxidants thrice daily for 6 weeks and observed improvements and amelioration of the symptoms. Kumar ${ }^{75}$ advocated Lycopene $(16 \mathrm{mg})$ and concluded that it produced better response. The process of carcinogenesis is known to occur through the generation of Reactive Oxygen Species, which acts through the initiation of lipid peroxidation (LPO). Antioxidants are used to prevent LPO-mediated harm and it has also been reported that antioxidant supplementation can effectively treat oral premalignant lesions. ${ }^{77}$

\section{Steroids}

Sinha and Jain ${ }^{77}$ have tried local injection of hydrocortisone $1.5 \mathrm{cc}$ and found hydrocortisone to be effective. Moreover Kakar et al., ${ }^{78}$ found that injection of Dexamethasone (4 mg) and $1500 \mathrm{IU}$ of hyaluronidase locally for 7 weeks gave superior results if it is followed by 3 weeks of hyaluronidase.

\section{Enzymes}

Collagenase is a lysosomal enzyme, $\operatorname{Lin}$ and $\operatorname{Lin}^{79}$ found that intralesional injection of collagenase resulted in significant improvement. Gupta and Sharma ${ }^{66}$ gave injected Chymotrypsin (5000 IU), hyaluronidase (1500 IU) and dexamethasone (4 mg) twice weekly for 10 weeks sub-mucosally and observed good results.

\section{Vasodilator}

Occlusive blood vessels encountered in OSMF restrict nutrients and therapeutic substances from reaching the affected tissue, which may be one of the reasons for the unsatisfactory therapeutic effect of drug treatment of OSF.Lai (1995) ${ }^{80}$ has carried out treatment for OSMF using buflomedial HCL ( 3 tablets of $450 \mathrm{mg}$ each per day) and topical trimacenoloneacetonide $0.1 \%$ on mucosal ulcers at bed time and observed positive results. Rajendran (2006) ${ }^{81}$ used pentoxifylline, a methylxanthine derivative that has vasodialating properties. It was administered as $400 \mathrm{mg}$ thrice daily for a period of more than 12 months and observed improvement in symptoms of OSMF. Buflomedial HCL (peripheral vasodialator) has been found to affect the tissues in diffuse fibrosis to a noticeable degree by the relief of local ischemic effect. ${ }^{82}$

\section{Placental extract}

The injection placentrax is an aqueous extract of human placenta. The action of placental extract is essentially biogenic stimulation and its use is based on the tissue therapy method ${ }^{(82)}$. Ramanjaneyalu and PrabhakarRao (1980) advocated 2 cc placentrax injection at weekly interval for 10 weeks. They have found it to be superior to Cortisone. They have even found two cortisone resistant cases responded well to placentrax. ${ }^{83}$

Furthermore Katharia et al., (1992) also carried out a study on 22 OSMF patients and injection of $2 \mathrm{ml}$ Placental extract (Inj. Placentrex) was given locally in the predetermined areas, once a week up to a total duration of one month. Effects were monitored in reducing the severity of the disease. ${ }^{84}$

\section{Physiotherapy}

Cox and Zoellner (2009) advocated five times daily physiotherapy by inter-positioning tongue spatulas between teeth and adding a new spatula every 5-10 days for 4 months and observed improved oral opening. ${ }^{85}$

\section{Surgical management}

Management of stage III and IV patients is challenging in terms of restoring inter-incisal distance. A wide range of treatments such as medicinal management, surgical therapy, and physiotherapy have been discussed in literature but with varying results. ${ }^{1,9,86}$ Surgical treatment is indicated in patients with severe trismus and/or biopsy results revealing any dysplastic or neoplastic changes. Surgical modalities that have been 
used include the following: Simple excision of the fibrous bands, excision of bands with myotomy with orwithout coronoidectomy, coverage of the raw area with skin grafts, fresh amnion, collagen membrane, buccal pad of fat, local flaps or vascularizedfree flaps, followed by active post-operative jaw physiotherapy with antioxidants and proper nutrition and regular follow-ups to ensure maintenance of oral opening and early detection of malignant changes if any. ${ }^{54}$

Use of lasers for band excision also has been documented. The most common lasers used in primary incision were the ErYCCG laser ${ }^{87}$, KTP $532^{88}$, and the diode lasers. ${ }^{89}$

\section{Interpositional Grafts (Flaps)}

Use of interpositional grafts in areas of band excision havebeen the most widespread methods of surgical intervention in OSF. Common intraoral flaps are Tongue flaps, Palatal island flaps and Buccal fat pad; on the other hand Nasolabial flap and Temporalis fascia flap are most commonly used as extra oral flaps. ${ }^{7}$

Tongue flap-The use of a tongue flap is rather surprising in the treatment of OSMF. Apart from the short-term morbidity of the donor site in terms of speech and mastication, post-operative fibrosis and constriction of tongue mass can have deleterious effects on the lifestyle of the patient.The single longest follow up of surgically treated cases was published by Mehrotra et al. ${ }^{1}$ The authors used the tongue flap procedure for interpositionalgraft stabilization in $60 \mathrm{OSF}$ patients over a 7-year period. The authors reported good maintenance of oral opening and graft health extending through the follow up period. ${ }^{1}$ The bilateral tongue flaps cause severe dysphasia, disarticulation and carry the risk of post-operative aspiration. Also they provide limited amount of donor site tissue as their reach is in adequate. The stability of tongue flap and dehiscence are the common post-operative complications of uncontrolled tongue movement apart from this; reported involvement of the tongue is $38 \%$ which precludes its use for reconstruction. ${ }^{66}$

Palatal island flap-The palatal flap based on the greater palatine artery was used by Golhar et $\mathrm{al}^{90}$ in 33 patients of their series of 100 cases. This technique, accompanied with bilateral Temporalis myotomy and coronoidectomy, was a highly effective surgical procedure. ${ }^{61}$ However, use of island palatal flap has limitation such as its involvement of donor site fibrosis and second molar tooth extraction required for flap to cover without tension. ${ }^{24,68}$

Buccal Fat Pad- The buccal fat pad is a mass of specialized fatty tissuewhich is distinct from subcutaneous fat. It is termed syssarcosis-; it enhances intermuscular motion. It consists of a main body and five extensions: buccal, pterygopalatine, pterygomandibular, superficial and deep temporal. The body is centrally positioned and is located above the parotid duct and extends along the anterior border of masseter muscle. It courses medially to rest on the periosteum of the posterior maxilla and overlies the uppermost fibres of buccinator muscle. The buccal extension lies superficially within the cheek. The superficial and deep temporal extensions reside in the temporal region. ${ }^{91}$ Yeh described the application of pedicledbuccal fat pad after incision of fibrous bands and suggested that this was a very logical, convenient, and reliable technique for treatment of oral submucous fibrosis. ${ }^{92}$

The numerous advantages of employing buccal fat pad include ease of accessibility through the very incision used for creating surgical defect, thereby obviating the necessity of an alternative donor site and its ensuing morbidity. The buccal fat pad as a donor tissue is not involved in the pathological process unlike other donor tissues such as the tongue or palate. It also improves the physiological functions of cheek by regaining its suppleness and elasticity post surgically. ${ }^{92}$ Buccal fat pad serves as a good substitute, because it provides excellent function without deteriorating the esthetics and the results obtained were sustained long term. Thus Lai DR et al considered this as the quickest and most efficient form of therapy for OSMF patients with severe trismus to ensure long-term improvement in mouth opening. ${ }^{9}$

Nasolabial Flap- The nasolabial flap proved to be the most popular procedure used in the surgical treatment of OSMF. Apart from the easy accessibility, the availability of a healthy vascular pedicle based on the inferior nasal vessels and the possibility of using this flap to cover almost all regions in the oral cavity make it a well justified choice for the treatment of OSMF. ${ }^{7}$ The nasolabial flap is typically classified as an axial pattern flap based on angular artery. It can be based superiorly or inferiorly. Most of the studies using the nasolabial 
flap reported post-operative oral openings of over 35 $\mathrm{mm}$ at the end of the follow up periods which ranged from 1 to 36 months. In the single largest study using nasolabial flaps David Tauro ${ }^{93}$ reported satisfactory oral opening of $40 \mathrm{~mm}$ postoperatively in his series of 85 cases. The common complications following this flap have been scars in the facial region, decrease or accentuation of the nasolabial fold and development of hair on the flap tissue in the intraoral region and also it cannot be extended adequately to cover the raw area. ${ }^{94}$

Temporalis Fascia Flap- The flap seems to be the least popular amongst all facial flaps preferred.Janjua et al $^{95}$ carried out this technique on five patients and reported good results. Theprocedure involved detachment of the masseter muscleinsertion in the zygomatic arch and temporalis attachmentto the coronoid process before the flap was raised. The flapwas then covered with a split skin graft. All five cases reported satisfactory uptake and maintained vascular supply. ${ }^{95}$

Distant Flaps - Interestingly use of free flaps for surgical management of OSMF has been reported only from the Chinese subcontinent with no reports available from other regions of the world. Five studies using a split technique of a radial forearm free flap from a single donor site and a single study using a similar split flap harvested from anterolateral thigh based on the lateral dorsal circumflex artery have been described. All the studies reported common complications of aberrant microvascular stenosis in the anastomoses and need for debulking at a later stage. ${ }^{93,96 .}$

Use of Grafts- Split skin grafts (SSG), collagen membranes and artificial dermis, human placenta and amnion have been the common materials preferred in the grafting of muco muscular defects in the surgical management of OSMF. ${ }^{95,97,98}$ The use of SSG, and allogenic materials is purely supportive and protective in the post-operative healing period. The use of commercially available dermis and collagen seems to be gaining popularity due to the ready availability and the decreased incidence of morbidity in donor sites when harvesting SSG. ${ }^{97,98}$

Fibrin glue is a biological tissue adhesive based on the final stage of coagulation wherein. Thrombin acting on fibrinogen converts it into fibrin. Thus, it has two components, fibrinogen and thrombin obtained from patient's own blood. Use of the fibrin glue is simple, safe, cost effective, and rapid technique. Its use to cover the raw areas after excision of fibrous bands is being tried at various institutes. ${ }^{54}$

Absorbable Atelocollagen Membrane is available as a sterile, pliable surgicalporous scaffold agent made of highlypurified type I atelocollagen derivedfrom porcine skin. It is being used forcoverage of the raw areas in non-healingand burn wounds. Itsadvantages include, bleeding control andstabilization of the blood clot,acceleration of the wound healingprocess, provides matrix for tissueingrowths, can be cut to fit any sizewound, soft and conformable to woundsite, maintains integrity in moist state, leaves wound free of fiber. Its use inOSMF is being tried in many institutesand long term results are awaited. ${ }^{54}$

Oral sub mucous fibrosis is one of the most unsatisfactorily treated diseases and definitely established as a pre-malignant oral conditionso there is an urgent need to initiate public health education measures to educate people about these debilitating oral pre-malignant condition before it is too late. Dentists can play a significant part in educating patients about the dangers of betel quid chewing and in the early diagnosis of such high-risk premalignant lesions and cancer.Regular oral checkups for pre-cancer and cancer should be conducted frequently during periodic oral examinations. Treatment must be combined with discontinuation of betel quid / tobacco chewing active jaw physiotherapy to correctly control early and advanced phases of OSMF.

\section{References}

1. Mehrotra D, Pradhan R, Gupta S. Retrospective comparison of surgical treatment modalities in 100 patients with oral submucous fibrosis. Oral Surg, Oral Med Oral Pathol Oral Radiol Endodontology. 2009; 107: p. 1-10.

2. Pindborg JJ, Sisrat SM. Oral submucous fibrosis. Oral Surg. 1966; 22: p. 764-779.

3. World Health Organization. Guide to epidemiology and diagnosis of oral mucosal diseases and conditions. community dent oral epidemiol. 1980; 8: p. 1-26.

4. Rajendra R. Oral submucous fibrosis: etiology, pathogenesis, and future research. Bull World Health Organ. 1994; 72: p. 985-996.

5. Aziz SR. Oral submucous fibrosis: case report and review of diagnosis and treatment. J Oral Maxillofac Surg. 2008; 66: p. 2386-9.

6. Angadi PV, Rao S. Management of oral submucous fibrosis: an overview. Oral Maxillofac Surg. 2010; 14: p. 133-142. 
7. Venkatesh VK. Surgical interventions in Oral Submucous Fibrosis: A systemic analysis of the literature. J Maxillofac Oral Surg. 2014; 14(3).

8. Saravanan K, Narayanan V. The use of buccal fat pad in the treatment of oral submucous fibrosis: a newer method. Int J Dent. 2012.

9. Lai DR, Chen HR, Lin LM, et al. Clinical evaluation of different treatment methods for oral submucous fibrosis: A 10-year experience with 150 cases. J Oral Pathol Med. 1995; 24: p. 402-6.

10. Trivedy CR, Craig G, Warnakulasuriya S. The oral health consequences of chewing area nut. Addict Biol. 2002; 7: p. 115-125.

11. Schwartz J. Atrophia Idiopathica (tropica) mucosae oris. In Eleventh International Dental Congress; 1952; London.

12. Joshi SG. Submucous fibrosis of the palate and pillers. Indian J Otolaryng. 1953; 4: p. 1-4.

13. Paymaster JC. Cancer of buccal mucosa; a clinical study of 650 cases in Indian patients. Cancer. 1956; 9: p. 431-5.

14. Angadi PV, Rao SS. Areca nut in pathogenesis of oral submcous fibrosis: revisited. Oral Maxillofac Surg. 2011; 15: p. 1-9.

15. Pindborg JJ, Chawla TN, Srivastava AN, Gupta D, Mehritra ML. Clinical aspects of oral submucous fibrosis. Acta Odontal Scand. 1964; 22: p. 679-691.

16. Cox SC, Walker DM. Oral submucous fibrosis: a review. Aust Dent J. 1996; 41(5): p. 294-299.

17. Gupta PC, Warnakulasuriya S. Global epidemiology of areca nut usage. Addict Biol. 2002; 7(1): p. 77-83.

18. Rajalalitha P, Vali S. Molecular pathogenesis of oral submucous fibrosis- a collagen metabolic disorder. J Oral Pathol Med. 2005; 34: p. 321-328.

19. Chiba I. Prevention of betel-quid chewers' oral cancer in Asian-Pacific area. Asian Pac J Cancer Prev. 2001; 2: p. 263-269.

20. Global adult tobacco survey Bangladesh report. Geneva: World Health Organization. [Online].; 2009 [cited 2019 July 29. Available from: https://www.who.int/tobacco/ surveillance/global_adult_tobacco_survey_bangladesh_ report_2009.pdf?ua=1.

21. Rudat K. Black and minority ethnic groups in England, health and lifestyle. In Health Education Authority; 1994; London.

22. Bedi R, Gilthorpe MS. The prevalence of betel-quid and tobacco chewing among the Bangladeshi community resident in a United Kingdom area of multiple deprivation. Primary Dental Care. 1995; 2: p. 39-42.

23. Summers RA, Williams SA, Curzon MEJ. The use of tobacco and betel quid ('pan') among Bangladeshi women in West Yorkshire. Community Dental Health. 1994; 11: p. 1216.
24. Pindborg JJ, Murti PR, Bhonsle RB, Gupta PC, Daftary DK, Metha FS. Oral submucous fibrosis as a precancerous condition. Scand J Dent Res. 1984; 92: p. 224-9.

25. Sinor PN, Gupta PC, Murti PR, Bhonsle RB, Daftary DK, Mehta FS, et al. A case-control study of oral submucous fibrosis with special reference to the etiologic role of areca nut. J Oral Pathol Med. 1990; 19: p. 94-8.

26. Seedat HA, Van Wyk CW. Beetle nut chewing and dietary habits of chewers without and with submucous fibrosis and with concomitant oral cancer. South Afr Med J. 1988; 74: p. $572-5$.

27. Maher R, Lee AJ, Warnakulasuriya KA, Lewis JA, Johnson NW. Role of areca nut in the causation of oral submucous fibrosis: A case control study in Pakistan. J Oral Pathol Med. 1994; 23: p. 65-9.

28. Jacob BJ, Straif K, Thomas G, Ramadas K, Mathew B, Zhang ZF, et al. Betel quid without tobacco as a risk factor for oral pre-cancers. Oral Oncol. 2004; 40: p. 697-704.

29. Pindborg JJ, Bhonsle RB, Murti PR, Gupta PC, Daftary DK, Mehta FS. Incidence and early forms of oral submucous fibrosis. Oral Surg Oral Med Oral Pathol. 1980; 50: p. 4044.

30. Farrand P, Rowe RM, Johnston A, Murdoch H. Prevalence, age of onset and demographic relationships of different areca nut habits amongst children in Tower Hamlets, London. Br Dent J. 2001; 190: p. 150-4.

31. Kiran K, Sarasvvathi TR, Rangnathan K, Devi Lima M, Joshua E. Oral submucous fibrosis: A clinicohistopathological study in Chennai. Indian J Dent Res. 2007; 18: p. 53-59.

32. Jain AK, Nigam R, Gupta R. Oral submucosal fibrosis - A clinicopathological study. J Evol Med Dent Sci. 2013; 2: p. 2984-9.

33. Angadi PV, Rekha KP. Oral submucous fibrosis: A clinicopathologic review of 205 cases in Indians. J Oral Maxillofac Surg. 2011; 15: p. 15-19.

34. Babu S, Bhat RV, Kumar PU, Sesikaran B, Rao KV, Aruna P, Reddy PR. A comparative clinico-pathological study of oral submucous fibrosis in habitual chewers of pan masala and betel quid. J Clin Toxicol. 1996; 34: p. 317-22.

35. Trivedy C, Baldwin D, Warnakulasuriya S, Johnson N, Peters T. Copper content in Areca catechu (betel nut) products and oral submucous fibrosis. Lancet. 1997; 349: p. 1447.

36. Anuj JA, Saumya TA. Oral Submucous Fibrosis in Pediatric Patients: A Systematic Review and Protocol for Management. International Journal of Surgical Oncology. 2019.

37. Merchant A, Husain SS, Hosain M et al. Paan without tobacco: an independent risk factor of oral cancer. International Journal of Cancer. 2000; 186(1): p. 128131. 
38. Murti PR, Bhonsie RB, Pindborg JJ et al. Malignant transformation rate in oral submucous fibrosis over a 17year period. Community Dental and Oral Epidemiology. 1985; 13: p. 340-341.

39. van Wyk CW, Grobler Rabie AF,Martell RW, Hammond MG. HLA antigens in oral submucous fibrosis. J Oral Pathol Med. 1994; 23: p. 23-27.

40. Maresky LS, de Waal J, Pretorius S,van Zyl AW, Wolfaardt P. Epidemiology of oral precancer and cancer. S Afr Med J. 1989; Suppl: p. 18-20.

41. Warnakulasuriya KA, Trivedy C, Maher R, Johnson NW. Aetiology of oral submucous fibrosis. Oral Dis. 1997; 3: p. 286-287.

42. Caniff JP, Harry W, Harris M. Oral submucous fibrosis: its pathogenesis and management. Br Dent J. 1986; 160: p. 429-34.

43. Tilakratne WM, Klinikowski MF, Saku T, Peters TJ, Warnakulasuriya S. Oral submucous fibrosis: review on etiology and pathogenesis. Oral Oncol. 2006; 42: p. 5618 .

44. Lal D. Diffuse oral submucous fibrosis. J All India Dent Assoc. 1953; 26(13): p. 14-15.

45. Murti PR, Bhonsle RB, Gupta PC,Daftary DK, Pindborg JJ, Metha FS. Aetiology of oral submucous fibrosis with special reference to the role of areca nut chewing. J Oral Pathol Med. 1995; 24: p. 145-52.

46. Seedat Ha, van Wyk CW. Betel-nut chewing and submucous fibrosis in Durban. S Afr Med J. 1998; 74: p. 568-571.

47. Ranganathan K, Uma Devi M, Joshua E, Kirankumar K, Saraswathi TR. Oral submucous fibrosis: a case control study in Chennai South India. J Oral Pathod Med. 2004; 33: p. 274-7.

48. Yang YH, Lee HY, Tung S, Shieh TY. Epidemiological survey of oral submucous fibrosis and leukoplakia in aborigines of Taiwan. J Oral Pathod Med. 2001; 30: p. $213-9$.

49. Shah N, Sharma PP. Role of chewing and smiking habits in the etiology on oral submucous fibrosis(OSF): a case control study. J Oral Pathod Med. 1998; 27: p. 475-9.

50. Merchant AT, Haider SM, Fikree FF. Increased severity of oral submucous fibrosis in young Pakistani men. Br J Oral Maxillofac Surg. 1997; 35: p. 284-7.

51. CANIFF JP, HARVEY W. The aetiology of oral submucous fibrosis. The stimulation of collagen synthesis by extracts of areca nut. Int J Oral Surg. 1981; 10.

52. HARVEY W, SCUTL A, MEGHJI S, CANIEF JR. Stimulation of human buccal mucosa fibroblasts in vitro by betel nut alkaloids. Arch Oral Biol. 1986; 31: p. 45-9.

53. JAYANTHI V MAYBERRY JE. Oral submucosal fibrosis a preventable disease. Gut. 1992; 33: p. 4-6.
54. Shevale VA, Kalra RI, Shevale VR, Shringapure MI. Management of oral submucous fibrosis: a review. Indian Journal of Dental Sciences. 2012 June; 4.

55. Rajendran R. Oral Submucous Fibrosis. J Oral Maxillofac Pathol. 2003; 7: p. 1-4.

56. Pindborg JJ. Oral submucous fibrosis: a review. Ann Acad Med Singapore. 1989; 18: p. 603-7.

57. Shiau YY, Kawan HW. Submucous Fibrosis in Taiwan. Oral Surg Oral Med Oral Pathol. 1979; 47: p. 454-457.

58. Morawetz G. Katsikeris N, Weinberg S, Listorm R. Oral submucous fibrosis. Int J Oral Maxxilofac Surg. 1987; 16: p. 609-714.

59. Yusuf H, Yong L. Oral submucous fibrosis in a 12-year-old Bangladeshi boy: a case report and review of literature. International Journal of Paediatric Dentistry. 2002; 12: p. 271-276.

60. Canniff JP, Harvey W, Harris M. Oral submucous fibrosis: its pathogenesis and management. British Dental Journal. 1986; 160: p. 429-34.

61. KhannaJN,Andrade NN. Oral submucous fibrosis a new concept in surgical management: A report of 100 cases. Int J Oral maxillofac surg. 1995; 24: p. 433-439.

62. Pindborg JJ, Mehra FS, Daftary DK. Incidence of oral cancer among 30,000 villages in India in a 7 year follow up study of oral precancerous lesions. Community Dent Oral. 1975; 3: p. 86-8.

63. S. M. Haider, A. T. Merchant,F. F Fikree,M. H. Rahbar. Clinical and functional staging of oral submucous fibrosis. British Journal of Oral and Maxillofacial Surgery. 2000; 38: p. 12-15.

64. Borle RM, Borle SR. Management of oral submucous fibrosis: a conservative approach. J Oral Maxillofac Surg. 1991; 41: p. 788-91.

65. Fedorowiccz $Z$ et.al. Lack of reliable evidence for oral sub mucous fibrosis treatment. Evidence based dentistry. 2009; 10: p. $8-9$.

66. Gupta D, Sharma SC. Oral submucous fibrosis-a new treatment regimen. J Oral Maxillofac Surg. 1988; 46: p. $830-3$.

67. Jiunn Tat Lee et al. A double -skin paddle radial forearm flap for the reconstruction of oral submucous fibrosis. Tzu chi Med J. 2006; 18(5): p. 362-369.

68. Yen DJC. Surgical tretement of sub mucous fibrosis. Oral Surg. 1982; 54: p. 269-72.

69. Ajit Auluck, Miriam P. Rosin, Lewei ZH, Sumanth KN. Oral Submucous Fibrosis, a Clinically Benign but Potentially Malignant Disease: Report of 3 Cases and Review of the Literature. JCDA. 2008 October; 74(8): p. 735-740.

70. Anil K, Sharma SC, Sharma P, Om Chandra, Singhal KC, Nagar A. Beneficial role of zinc in the treatement of oral submucous fibrosis. Indian J pharmac. 1991; 23: p. 236-41. 
71. Balaji Rao B. Oral Sub Mucous Fibrosis - The Davangere study. JIAOMR. 1993; 4: p. 11.

72. Reddi R. Oral Submucous Fibrosis - A recent trend in its treatment. JIAOMR. 1993; 4: p. 7-8.

73. Singh N, Singh J, Singh U. Oral Sub Mucous Fibrosis. A New Approach to treatment with combined therapy. J Indian Dent Assoc. 1996; 67: p. 168-70.

74. Gupta S, Reddy MVR, Harinath BC. Role of oxidative stress and antioxidants in aetiopathogenesis and management of oral submucous fibrosis. Indian J Clin Biochem. 2004; 19: p. $138-141$.

75. Kumar A, Bagewadi A, Keluskar V, Singh M. Efficacy of lycopene in the management of oral submucous fibrosis. Oral Surg Oral Med Oral Pathol Oral Radiol Endod. 2007; 103: p. 207-13.

76. Garewal HS. Response of oral leukoplakia to beta carotene. J Clin Oncol. 1990; 8: p. 1717-20.

77. Sinha SN, Jain PK. Intra oral injection of hydrocortisone and placentrax in Oral Sub Mucous Fibrosis. Indian Journal of Otolaryngol. 1978; 30: p. 103.

78. Kakar PK, Puri RK, Venkatchalam VP. Oral sub mucous fibrosis treatment with Hyalase. J Laryngol Otol. 1985; 99: p. 57-9.

79. Jing Hu, Xiaowen Jiang. Drug Treatment of Oral Submucous Fibrosis: A Review of the Literature. J Oral Maxillofac Surg. 209; 67: p. 1510-5.

80. Lai DR, Chen HR, Lin LM, Huang YL, Tsai CC. Clinical evaluation of different treatment methods for oral submucous fibrosis. A 10-year experience with 150 cases. J Oral Pathol Med. 1995; 24: p. 402-6.

81. Rajendran R, Rani V, Shaikh S. Pentoxifylline therapy: A new adjunct in the treatment of oral submucous fibrosis. Indian J Dent Res. 2006; 17: p. 190-8.

82. Jyothi TA, Kumar SA, Mamatha GP. Non-invasive management of Oral submucous fibrosis: a review. Journal of Oral Health Research. 2011 January; 2(1).

83. Ramanjaneyulu P, Prabhakar Rao. Submucous Fibrosis: New Treatment. Indian Dent Assoc. 1980; 52: p. 379-80.

84. Katharia SK, Singh SP, Kulshreshtha VK. The effects of placental extract in management of oral submucous fibrosis. Indian J Pharmac. 1992; 24: p. 181-3.

85. Cox S, Zoellner H. Physiotherapeutic treatment improves oral opening in oral submucous fibrosis. J Oral Pathol Med. 2009; 38: p. 220-6.
86. Jiang $X, H u$ J. Drug treatment of oral submucous fibrosis: a review of the literature. J Oral Maxillofac Surg. 2009; 67: p. $1510-1515$.

87. Chaaya VA, Sinha V, Rathor R, Modi N, Rashmi GS, Parmar $\mathrm{V}$ et. al. Oral submucous fibrosis surgical treatment with CO2 laser. World Artic Ear Nose Throat. 2010; 3: p. 1-2.

88. Chaudhary Z, Verma M, Tandon S. Treatment of oral submucous fibrosis with ErCr:YSGG laser. Indian J Dent Res. 2011; 22: p. 472-4.

89. Nayak DR, Mahesh SG, Agrawal D, Pavithran P, Pujary K, Pillai S. Role of KTP-532 laser in management of oral submucous fibrosis. J Laryngol Otol. 2009; 123: p. 418421.

90. Golhar S, Mahore MN, Narkhede S. Tongue flap in oral submucous fibrosis. Indian J Otolaryngol Head Neck Surg. 1989; 41: p. 104-107.

91. Kumar, et al. Buccal fat pad reconstruction for oral submucous fibrosis. National Journal of Maxillofacial Surgery. 2010 December; 1(2): p. 165.

92. Yeh CJ. Application of the buccal fat pad to the surgical treatment of Oral Submucous Fibrosis. Int J Oral Maxillofac Surg. 1996; 25: p. 130-3.

93. Tauro DP. A unique melolabial flap in the surgical management of oral submucous fibrosis - "the sea gull flap" - an experience with 85 cases: A clinical study. Int J Oral Maxillofac Surg. 2009; 38: p. 508-512.

94. Divya Mehrotra, R. Pradhan, Shalini Gupta. Retrospective comparison of surgical treatment modalities in 100 patients with oral submucous fibrosis. Oral Surg Oral Med Oral P a t h o 1 Or a 1 Ra d i o 1 En d o d. 2007; 107.

95. Janjua OS, Bukhari SGA, Ibrahim MW, Mehmood S, Sarfraz T. Oral submucous fibrosis - reconstruction with nasolabial flap. Pak Armed Forces Med J. 2011; 2: p. 1-3.

96. Kavarana NM, Bhathena HM, Griffiths RW. Surgery for severe trismus in submucous fibrosis. Plast Reconstr Surg. 1989; 83: p. 401-403.

97. Chang Y-M, Tsai C-Y, Kildal M, Wei F-C. Importance of coronoidectomy and masticatory muscle myotomy in surgical release of trismus caused by submucous fibrosis. Plast Reconstr Surg. 2004; 113: p. 1949-1954.

98. Chao C-K, Chang L-C, Liu S-Y, Wang J-J. Histologic examination of pedicled buccal fat pad graft in oral submucous fibrosis. J Oral Maxillofac Surg. 2002; 60: p. 1131-1134.

99. Gururaj AR, Peter A. BR. Oral submucous fibrosis: an overview of the aetiology, pathogenesis, classification, and principles of management. British Journal of Oral and Maxillofacial Surgery. 2013; 51: p. 587-593. 